\title{
Oxidative Conversion of Lactic Acid by Chloramine-T in Sulfuric Acid Medium: a Kinetic and Mechanistic Study
}

\author{
V. S. Kiranmai Kolachana ${ }^{1}$, Kishore Cholkar ${ }^{1}$, Waseem M. Kayani ${ }^{1}$, Gilles K. Kouassi ${ }^{1}$, \\ R.V. Jagadeesh ${ }^{2}$, Netkal M. Made Gowda* \\ ${ }^{1}$ Department of Chemistry, One University Circle, Western Illinois University, Macomb, IL 61455, USA \\ ${ }^{2}$ Leibniz Institute for Catalysis, the University of Rostock, Rostock, Germany
}

\begin{abstract}
Lactic acid or LA $\left(\mathrm{C}_{3} \mathrm{H}_{6} \mathrm{O}_{3}\right)$ plays a major role in several biomedical processes and in organic syntheses. The stoichiometry of the LA-chloramine-T (CAT) reaction in sulfuric acid medium shows that two moles of CAT are consumed per mole of LA with carbon dioxide, acetic acid, and $p$-toluenesulfonamide (PTS) as main products. The oxidation of LA by CAT in acid solutions has been spectrophotometrically monitored at $\lambda_{\max }=255 \mathrm{~nm}$ at $323 \mathrm{~K}$. The reaction, studied under pseudo-first order conditions of $[\mathrm{LA}]_{0}>>[\mathrm{CAT}]_{0}$, follows a first-order dependence of the rate on $[\mathrm{CAT}]$ and a fractional order on [LA]. Variations of the $[\mathrm{PTS}],\left[\mathrm{H}^{+}\right],\left[\mathrm{SO}_{4}{ }^{2-}\right]$, dielectric constant, and ionic strength of the reaction medium have no effect on the rate. Kinetic and activation parameters are evaluated based on the temperature effect on the rate. A mechanism consistent with the observed kinetics and activation data has been proposed leading to the derived rate law.
\end{abstract}

Keywords Lactic Acid, Chloramine-T, Oxidation, Reduction, Spectrophotometry, Stoichiometry, Mechanism, Rate Law, P-Toulenesulfonamide, Kinetics

\section{Introduction}

Lactic acid (LA) is a naturally occurring organic acid, which is a monomer of polylactic acid. The focus of the US market is on the production of lactic acid, due to its variety of applications such as in food processing[2], biomedical products[3], and textiles[4]. It also finds applications in the manufacture of bio-plastics, fibers, solvents, and oxygenated chemicals[1,5-7], Furthermore, polymeric lactic acid ester, polylactide (PLA), has a number of biomedical applications in products such as sutures, stents, dialysis media and drug delivery devices[8].

Aromatic sulfonylhaloamines such as chloramine-T (CAT), chloramines-B (CAB), and bromamine-T (BAT) contain a polar $\mathrm{N}$-halo bond, which is capable of forming a halonium $\left(\mathrm{X}^{+}\right)$ion in solutions. This electrophilic species can function as an oxidizing and halogenating agent in solutions. Inorganic chloramines are the byproducts formed in drinking water due to chlorination[9]. Chloramines can be used as bleaching agents, disinfectants and oxidants. During the water disinfection, chloramines can improve the odor and flavor of water[10] by oxidizing the environmental sulfur and other contaminations[11]. Aromatic sulfonylhaloamines are widely used in chemistry[12-14] to study the oxidation reaction mechanisms for a variety of substrates. Other oxi-

* Corresponding author:

gn-made@wiu.edu (Netkal M. Made Gowda)

Published online at http://journal.sapub.org/ajoc

Copyright (C) 2012 Scientific \& Academic Publishing. All Rights Reserved dants such as water-soluble (colloidal) manganese dioxide have been previously used to study the oxidation of lactic acid[15]. A literature search showed no reports on the mechanism of oxidation of LA by CAT in acid solutions. Hence, it was decided to spectrophotometrically investigate the kinetics and mechanism of oxidation of LA by CAT in sulfuric acid solutions.

\section{Experimental}

Lactic acid from Acros Co, USA was used as supplied ( $99.9 \%$ purity) to prepare the standard aqueous solutions and stored at $4^{\circ} \mathrm{C}$ until further use. Chloramine-T (Aldrich Chemical Co., USA), sodium thiosulfate (Spectrum Chemicals, USA), potassium iodide and iodate (both MCB reagents) were used. All chemicals were of accepted analytical grades of purity. Double distilled water was used in all solutions for the experiments.

\section{Kinetic Measurements}

Kinetic runs were performed under pseudo-first order conditions with a large excess of the substrate, LA, over the oxidant, $\mathrm{CAT}$, at $50^{\circ} \mathrm{C}$. For each run, requisite amounts of solutions of LA and sulfuric acid were mixed in a $50.0 \mathrm{~mL}$ volumetric flask. To this solution mixture, a measured amount of a standard concentrated CAT solution was added to give a desired overall concentration. Enough water was added to the flask to make-up the final volume to $50.0 \mathrm{~mL}$. The reaction mixture was stirred for uniform concentrations and thermostatted in a water bath at $50^{\circ} \mathrm{C}$ for $10 \mathrm{~min}$ to allow 
thermal equilibration. Photocell (1.0 cm path-length) containing the above reaction mixture was placed in the thermostatted $\left(50^{\circ} \mathrm{C}\right)$ chamber of the Shimadzu UV-Vis spectrophotometer (model 1601) connected to a computer and the course of reaction was monitored by measuring its absorbance at $\lambda_{\max }=255 \mathrm{~nm}$ at varying time intervals. The pseudo-first-order rate constant, $\mathrm{k}^{\prime}$ or $\mathrm{k}_{\mathrm{obs}}$, was obtained from the slope of the linear plot of $\ln$ (absorbance) vs. time. Each run was performed in duplicate and the average of the two values was considered.

\section{Reaction Stoichiometry}

Reaction mixtures containing $[\mathrm{CAT}]_{0}>>[\mathrm{LA}]_{0}$ in $0.05 \mathrm{M}$ $\mathrm{H}_{2} \mathrm{SO}_{4}$ were kept at $50^{\circ} \mathrm{C}$ with stirring for varying time intervals ranging from $1 \mathrm{~h}$ to $48 \mathrm{~h}$. At the end of each time period, the unreacted CAT remaining in the reaction mixture was titrated iodometrically against a standardized thiosulfate solution using $1 \%$ starch solution as an indicator near the endpoint. It showed that two moles of CAT were consumed per mole of LA resulting in the formation of acetic acid, carbon dioxide, sodium chloride, and $p$-toluenesulfonamide (PTS) as products.

\section{Product Analysis}

A reaction mixture with $[\mathrm{CAT}]_{0}>>[\mathrm{LA}]_{0}$ was stirred for $48 \mathrm{hrs}$ at $50^{\circ} \mathrm{C}$ for product analysis. The $\mathrm{pH}$ of the reaction mixture was raised to $8-9$ by the addition of $1.00 \mathrm{M} \mathrm{NaOH}$ solution before liquid-liquid extractions. These were performed thrice using dichloromethane-petroleum ether mixture $(1: 1 \mathrm{v} / \mathrm{v})$. The organic layer was rotary evaporated to obtain PTS as a dry residue while the aqueous layer retained polar products, acetic acid, $\mathrm{NaCl}$ and unreacted CAT. The reduction product, PTS, was further recrystallized in diethyl ether and identified using a gas-chromatography mass spectrometer (GC/MS). The CAT reduction product, PTS, was analyzed on a Shimadzu GC/MS (model \# 5050) under the following conditions: temp. $=80^{\circ}-250^{\circ} \mathrm{C}$ and pressure $=72$ $\mathrm{kPa}$. The mass spectrum showed a parent $\mathrm{M}^{+}$ion peak at 171 amu confirming PTS. The aqueous fraction consisting of acetic acid, $\mathrm{NaCl}$ and unreacted $\mathrm{CAT}$ was extracted with ethyl acetate $(1: 1 \mathrm{v} / \mathrm{v})$ thrice. ${ }^{1} \mathrm{H}-\mathrm{NMR}$ data revealed the identity of the main oxidation product, acetic acid. Another oxidation product, $\mathrm{CO}_{2}$, was detected by its conventional lime water test. The presence of chloride was detected by its $\mathrm{AgNO}_{3}$ reaction precipitating $\mathrm{AgCl}$ in solution.

\section{Test for free radicals}

Under the inert atmosphere of nitrogen, a freshly prepared $10 \%$ solution of acrylamide or acrylonitrile monomer was added to the LA-CAT reaction mixtures in $0.05 \mathrm{M} \mathrm{H}_{2} \mathrm{SO}_{4}$ in flasks, which were kept overnight in dark to prevent photochemical effects. Suitable controls without LA, CAT, and the LA-CAT mixture were used under similar conditions for comparison. The reaction mixture was monitored for the in situ formation of free radicals. A lack of turbidity due to non-polymerization of the monomer indicated the absence of free radicals.

\section{Results and Discussion}

Reaction Stoichiometry. Preliminary results showed that two moles of $\mathrm{CAB}$ were consumed per mole of LA resulting in the formation of acetic acid and PTS as the main oxidation and reduction products, respectively. The 2:1 reaction stoichiometry is shown in eq. (1) below.

$$
\begin{aligned}
& 2 \mathrm{ArSO}_{2} \mathrm{NClNa}+\mathrm{CH}_{3} \mathrm{CH}(\mathrm{OH}) \mathrm{COOH}+\mathrm{H}_{2} \mathrm{O} \\
& {[\mathrm{CAT}] \quad[\mathrm{LA}]} \\
& \stackrel{\mathrm{H}^{+}}{\longrightarrow} 2 \mathrm{ArSO}_{2} \mathrm{NH}_{2}+\mathrm{CH}_{3} \mathrm{COOH}+\mathrm{CO}_{2}+2 \mathrm{NaCl}(1) \\
& {[\mathrm{PTS}]}
\end{aligned}
$$

\section{Kinetics}

Effect of CAT on the reaction rate. Under the pseudo first-order conditions, $[\mathrm{LA}]_{0}>>[\mathrm{CAT}]_{\mathrm{o}}$, at constant $\left[\mathrm{H}_{2} \mathrm{SO}_{4}\right]$ and temperature, the $[\mathrm{CAT}]_{\mathrm{o}}$ was varied from $0.2-2.0 \mathrm{mM}$. Plots of $\ln$ (abs.) vs. time were linear indicating a first-order dependence of the rate on [CAT] (Fig. 1). Pseudo-first-order rate constants $\left(\mathrm{k}^{\prime}\right)$ calculated from the slopes of $\ln (\mathrm{abs}$.)-time plots are presented in Table 1. Rate constants remained constant with the increase in [CAT], further confirming the first-order rate dependence on [CAT].

Effect of $L A$ on the reaction rate. Under constant $[\mathrm{CAT}]_{\mathrm{o}}$, $\left[\mathrm{H}_{2} \mathrm{SO}_{4}\right]$ and temperature, the $[\mathrm{LA}]_{\mathrm{o}}$ was varied from 5.00 $\mathrm{x} 10^{-3} \mathrm{M}$ to $8.00 \times 10^{-2} \mathrm{M}$. An increase in the rate was observed with an increase in [LA] (Table 1). A linear plot of $\ln$ [LA] vs. ln $\mathrm{k}^{\prime}$ (Fig. 2) with a slope of 0.80 showed a fractional order dependence on [LA].

Effect of $\mathrm{H}_{2} \mathrm{SO}_{4}$ on the reaction rate. The concentration of sulfuric acid was varied from $1.00 \times 10^{-2} \mathrm{M}$ to $2.50 \times 10^{-1} \mathrm{M}$ while keeping all the other conditions in the reaction constant. The rate constant remained approximately the same (Table 1) indicating a zero effect of $\left[\mathrm{H}_{2} \mathrm{SO}_{4}\right]$ or $\left[\mathrm{H}^{+}\right]$on the rate (Fig. 1).

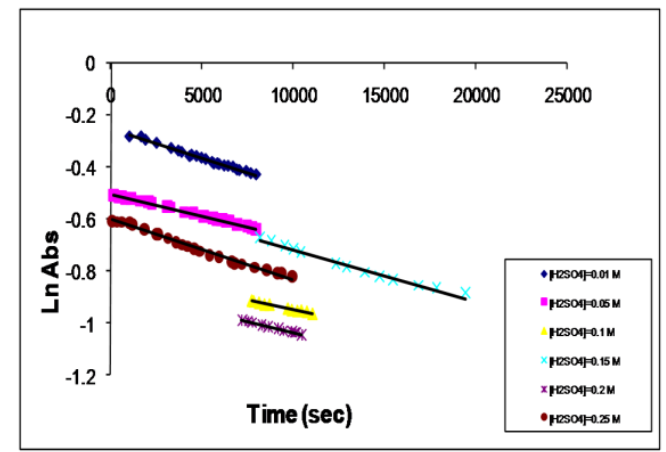

Figure 1. First-order plots with nearly constant slopes for different $\left[\mathrm{H}_{2} \mathrm{SO}_{4}\right] .1 .00 \times 10^{-2} \mathrm{M}$ to $2.50 \times 10^{-1} \mathrm{M}$

Effect of $\mathrm{Na}_{2} \mathrm{SO}_{4}$ on the reaction rate. Varying the ionic strength using $\mathrm{Na}_{2} \mathrm{SO}_{4}$ in the range $0.100 \mathrm{M}-1.50 \mathrm{M}$ at constant conditions, the reaction rate had negligible effect (Table 1). As a result, a constant ionic strength was not maintained in the reaction mixtures of other runs.

Effect of reduction product, PTS, on the reaction rate. The effect of the externally added reduction product, PTS, on the rate at other constant conditions was studied in the range, $1.00 \times 10^{-4} \mathrm{M}$ to $7.50 \times 10^{-3} \mathrm{M}$ PTS. Results presented in Table 1 show an insignificant effect of [PTS] on the reaction rate. 
Table 1. Effects of chloramine-T (CAT), Lactic acid (LA), and $\mathrm{H}_{2} \mathrm{SO}_{4}$ on the Reaction Rate at $323 \mathrm{~K}$

\begin{tabular}{|c|c|c|c|c|}
\hline$[\mathrm{CAT}]_{\mathrm{o}}\left(10^{-3} \mathrm{M}\right)$ & {$[\mathrm{LA}]_{\mathrm{o}}\left(10^{-2} \mathrm{M}\right)$} & {$\left[\mathrm{H}_{2} \mathrm{SO}_{4}\right]\left(10^{-1} \mathrm{M}\right)$} & $\mathrm{k}^{\prime}\left(10^{-5} \mathrm{~s}^{-1}\right)$ & \\
\hline 0.200 & 1.00 & 1.00 & 2.10 & \\
\hline 1.00 & 1.00 & 1.00 & 1.67 & \\
\hline 1.50 & 1.00 & 1.00 & 1.00 & \\
\hline 2.00 & 1.00 & 1.00 & 1.13 & \\
\hline 10.00 & 1.00 & 1.00 & 1.82 & \\
\hline 1.00 & 0.50 & 0.50 & 0.23 & \\
\hline 1.00 & 1.00 & 1.00 & 0.39 & \\
\hline 1.00 & 2.00 & 2.00 & 1.35 & \\
\hline 1.00 & 4.00 & 4.00 & 1.67 & \\
\hline 1.00 & 8.00 & 8.00 & 1.77 & \\
\hline 1.00 & 1.00 & 1.00 & 2.25 & \\
\hline 1.00 & 1.00 & 1.00 & 1.67 & \\
\hline 1.00 & 1.00 & 1.00 & 1.98 & \\
\hline 1.00 & 1.00 & 1.00 & 1.71 & \\
\hline 1.00 & 1.00 & 1.00 & 2.29 & \\
\hline 1.00 & 1.00 & 1.00 & 1.67 & \\
\hline 1.00 & 1.00 & 1.00 & 1.67 & $(1.19)^{\mathrm{a}}$ \\
\hline 1.00 & 1.00 & 1.00 & 1.67 & $(1.15)^{\mathrm{a}}$ \\
\hline 1.00 & 1.00 & 1.00 & 1.67 & $(1.75)^{\mathrm{b}}$ \\
\hline 1.00 & 1.00 & 1.00 & 1.67 & $(1.50)^{\mathrm{b}}$ \\
\hline 1.00 & 1.00 & 1.00 & 1.67 & $(1.69)^{\mathrm{b}}$ \\
\hline 1.00 & 1.00 & 1.00 & 1.67 & $(2.12)^{\mathrm{c}}$ \\
\hline 1.00 & 1.00 & 1.00 & 1.67 & $(2.46)^{\mathrm{c}}$ \\
\hline 1.00 & 1.00 & 1.00 & 1.67 & $(2.23)^{\mathrm{c}}$ \\
\hline
\end{tabular}

a: Values in parentheses refer to ionic strength variation: $\left[\mathrm{Na}_{2} \mathrm{SO}_{4}\right]=0.100 \mathrm{M}-1.50 \mathrm{M}$.

$\mathrm{b}$ : Values in parentheses refer to variation of $[\mathrm{PTS}]=1.00 \times 10^{-4} \mathrm{M}-7.50 \times 10^{-3} \mathrm{M}$

c: Values in parentheses refer to variation of $\mathrm{MeOH}$ content in the solvent medium: $5 \%, 15 \%$ and $25 \%$

Effect of dielectric constant. The effect of dielectric constant (D) of the solvent medium was determined using the $\mathrm{MeOH}-$ water solvent system. An increase in the $\mathrm{MeOH}$ content $(5-25 \% \mathrm{v} / \mathrm{v})$ showed no significant change in the reaction rate (Table 1$)$.

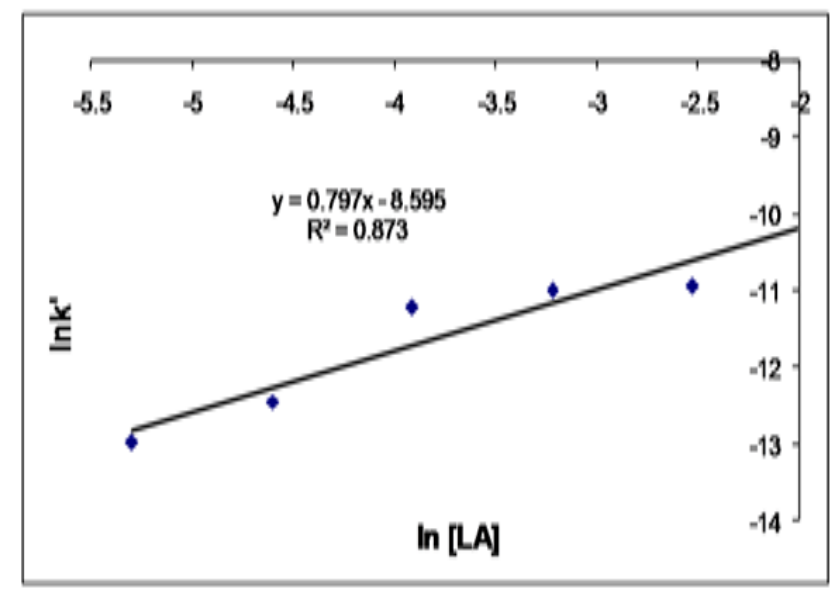

Figure 2. Ln-ln plot for the determination of the LA order

Effect of temperature. Kinetic runs were performed at various temperatures $(303-328 \mathrm{~K})$ while keeping the other experimental conditions the same. An Arrhenius plot of $\ln \mathrm{k}^{\prime}$ vs. 1/T (Fig. 3) and an Eyring plot of $\ln \left(\mathrm{k}^{\prime} / \mathrm{T}\right)$ vs. 1/T (Fig. 4) were used to calculate the activation parameters, namely, energy of activation $\left(E_{a}\right)$, entropy of activation $\left(\Delta S^{\ddagger}\right)$, enthalpy of activation $\left(\Delta \mathrm{H}^{\ddagger}\right)$, and free energy of activation $\left(\Delta \mathrm{G}^{\mp}\right)$. These results are summarized in Table 2.

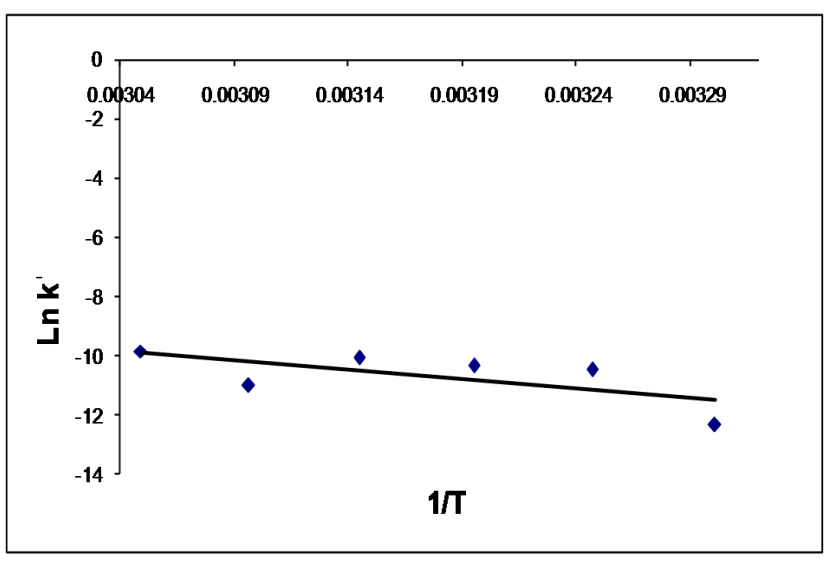

Figure 3. Arrhenius plot of $\ln \mathrm{k}^{\prime} v s .1 / \mathrm{T}$

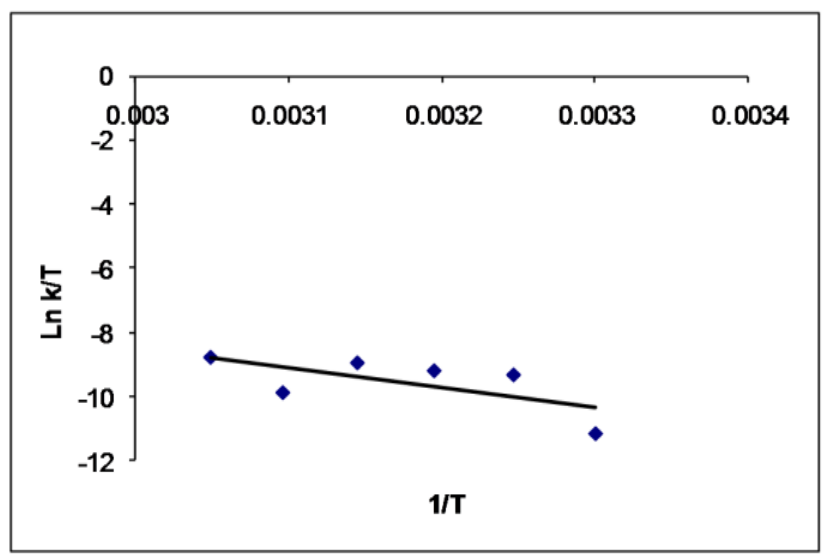

Figure 4. Eyring plot of $\ln \left(\mathrm{k}^{\prime} / \mathrm{T}\right) v s .1 / \mathrm{T}$ 
Table 2. Rate constants $\left(\mathrm{k}^{\prime}\right)$ at different temperatures and activąion parameters for the lactic acid oxidation by CAT in acid solutions

\begin{tabular}{|c|c|}
\hline Temperature Or Activation parameter & $\mathrm{k}^{\prime}\left(10^{-5} \mathrm{~s}^{-1}\right)$ \\
\hline $303 \mathrm{~K}$ & 0.43 \\
\hline $308 \mathrm{~K}$ & 2.79 \\
\hline $313 \mathrm{~K}$ & 3.22 \\
\hline $318 \mathrm{~K}$ & 4.21 \\
\hline $323 \mathrm{~K}$ & 1.66 \\
\hline $328 \mathrm{~K}$ & 5.18 \\
\hline $\mathrm{E}_{\mathrm{a}}\left(\mathrm{kJ} \mathrm{mol}^{-1}\right)$ & 53.7 \\
\hline$\Delta \mathrm{H}^{\mp}\left(\mathrm{kJ} \mathrm{mol}^{-1}\right)$ & 51.1 \\
\hline$\Delta \mathrm{S}^{\mp}\left(\mathrm{JK}^{-1} \mathrm{~mol}^{-1}\right)$ & -280 \\
\hline$\Delta \mathrm{G}^{\mp}\left(\mathrm{kJ} \mathrm{mol}^{-1}\right)$ & $142^{\mathrm{a}}$ \\
\hline
\end{tabular}

a, $\Delta \mathrm{G}^{\ddagger}$ value at $323 \mathrm{~K}$

*Reaction Conditions: $[\mathrm{CAT}]_{\mathrm{o}}=1.00 \times 10^{-3} \mathrm{M}$; $[\mathrm{LA}]_{\mathrm{o}}=4.00 \times 10^{-2} \mathrm{M}$; $\left[\mathrm{H}_{2} \mathrm{SO}_{4}\right]=0.100 \mathrm{M}$.

Detection of free radicals. The negative polymerization test with monomers for the detection of free radicals generated in situ in the reaction mixture showed the absence of free radicals.

Reaction mechanism. The observed stoichiometry of 2 mol CAT: $1 \mathrm{~mol}$ LA for the reaction in acid solutions, resulting in the formation of acetic acid and PTS as major products, is represented by eq. (1).

In aqueous solutions, CAT and its derivatives such as chloramine-B (CAB) and bromamine-T act as electrolytes. Some of the important equilibria exhibited by CAT and CAB are represented by the following eqs. (2)-(9) [16-28]:

$$
\begin{aligned}
& \mathrm{ArSO}_{2} \mathrm{NClNa} \rightleftharpoons \mathrm{ArSO}_{2} \mathrm{NCl}^{-}+\mathrm{Na}^{+} \\
& \mathrm{ArSO}_{2} \mathrm{NCl}^{-}+\mathrm{H}^{+} \rightleftharpoons \mathrm{ArSO}_{2} \mathrm{NHCl} \\
& 2 \mathrm{ArSO}_{2} \mathrm{NHCl} \rightleftharpoons \mathrm{ArSO}_{2} \mathrm{NH}_{2}+\mathrm{ArSO}_{2} \mathrm{NCl}_{2} \\
& \mathrm{ArSO}_{2} \mathrm{NHCl}^{-}+\mathrm{H}^{+} \rightleftharpoons \mathrm{ArSO}_{2} \mathrm{NH}_{2} \mathrm{Cl}^{+} \\
& \mathrm{ArSO}_{2} \mathrm{NHCl}+\mathrm{H}_{2} \mathrm{O} \rightleftharpoons \mathrm{ArSO}_{2} \mathrm{NH}_{2}+\mathrm{HOCl} \\
& \mathrm{ArSO}_{2} \mathrm{NCl}_{2}+\mathrm{H}_{2} \mathrm{O} \rightleftharpoons \mathrm{ArSO}_{2} \mathrm{NHCl}+\mathrm{HOCl} \\
& \mathrm{HOCl} \rightleftharpoons \mathrm{H}^{+}+\mathrm{OCl}^{-} \\
& \mathrm{HOCl}+\mathrm{H}^{+} \rightleftharpoons \mathrm{H}_{2} \mathrm{OCl}^{+}
\end{aligned}
$$

where $\mathrm{Ar}=p-\mathrm{Me}-\mathrm{C}_{6} \mathrm{H}_{4}$ for CAT and $\mathrm{Ar}=\mathrm{C}_{6} \mathrm{H}_{5}$ for CAB.

The free acid of CAT $\left(\mathrm{ArSO}_{2} \mathrm{NHCl}\right)$, dichloramine- $\mathrm{T}$ ( $\mathrm{ArSO}_{2} \mathrm{NCl}_{2}$ ), $\mathrm{HOCl}$, and $\mathrm{H}_{2} \mathrm{OCl}^{+}$are the probable oxidizing species in acid medium. As Eq. (6) indicates a slow hydrolysis, if $\mathrm{HOCl}$ were the primary oxidizing species, a firstorder retardation of the rate by the added $\mathrm{ArSO}_{2} \mathrm{NH}_{2}$ or PTS would be expected, which is contrary to the observed results of the LA-CAT reaction. Relative concentrations of the CAT species, which are $\mathrm{pH}$ dependent, present in acidified solutions of haloamines of comparable molarities proved $\mathrm{ArSO}_{2} \mathrm{NHCl}$ to be the oxidizing species in acid solutions[30]. If dichloramine- $\mathrm{T}$ were involved, the reaction rate would have shown a second-order dependence on it (eq. (4)), which is different from the determined first-order. Also, the PTS would have a negative effect, which was not shown by the observed results. Other probable CAT species could be eliminated on similar grounds. Further protonation of monohaloamines is possible below pH 2 as shown in eqs. (10) and (11) below for chloramine- $\mathrm{T}$ and chloramine- $\mathrm{B}$ [28-30].

$$
\begin{aligned}
\mathrm{CH}_{3} \mathrm{C}_{6} \mathrm{H}_{4} \mathrm{SO}_{2} \mathrm{NHCl}^{+}+\mathrm{H}^{+} \rightleftharpoons \mathrm{CH}_{3} \mathrm{C}_{6} \mathrm{H}_{4} \mathrm{SO}_{2} \mathrm{~N}^{+} \mathrm{H}_{2} \mathrm{Cl} \\
\mathrm{C}_{6} \mathrm{H}_{5} \mathrm{SO}_{2} \mathrm{NHCl}+\mathrm{H}^{+} \rightleftharpoons \mathrm{C}_{6} \mathrm{H}_{5} \mathrm{SO}_{2} \mathrm{~N}^{+} \mathrm{H}_{2} \mathrm{Cl}
\end{aligned}
$$

In the present study, the $\left[\mathrm{H}_{2} \mathrm{SO}_{4}\right]$ has no effect on rate. These results suggest that the free acid species, $\mathrm{ArSO}_{2} \mathrm{NHCl}$, is the most likely active oxidizing species involved in the mechanism of LA oxidation.

The experimental rate law involves a first-order dependence of the rate on $[\mathrm{CAT}]_{\mathrm{o}}$, a fractional-order on [LA], and a zero-order each on $\left[\mathrm{H}_{2} \mathrm{SO}_{4}\right]$ and [PTS]. Free radicals were not formed in the reaction mixtures. Furthermore, the rate was not affected by the ionic strength and dielectric constant of the reaction medium. On the basis of the above discussion, a simple mechanism (Scheme 1) has been proposed for the reaction in acidic solutions.

$$
\begin{aligned}
& \mathrm{ArSO}_{2} \mathrm{NHCl}+\mathrm{LA} \stackrel{K_{1}}{\rightleftarrows} X \quad \text { fast (i) } \\
& \text { (reactive CAT } \\
& \text { species) } \\
& X \\
& \text { (substrate) } \\
& \text { (complex) } \\
& \stackrel{k_{2}}{\longrightarrow} X^{\prime} \\
& +\mathrm{ArSO}_{2} \mathrm{NH}_{2} \\
& \text { (complex) } \\
& \text { (PTS) } \\
& \text { (complex) } \\
& \mathrm{X}^{\prime}+\mathrm{ArSO}_{2} \mathrm{NHCl} \stackrel{\mathrm{H}_{2} \mathrm{O}}{\longrightarrow} \cdots \rightarrow \text { Products }
\end{aligned}
$$

Scheme 1. Mechanistic steps for the LA oxidation by CAT in acid medium

Molecular structures of complexes $\mathrm{X}$ and $\mathrm{X}^{\prime}$, and other intermediate species formed are shown in Scheme 2. This scheme shows a detailed interpretation of electronic mechanism for the oxidation of $\mathrm{LA}$ by $\mathrm{ArSO}_{2} \mathrm{NHCl}$, which is the acidic reactive oxidizing species of CAT. In the fast pre-equilibrium (step (i)), there is an electrophilic attack of the chlorinium ion of the oxidant on the hydroxyl group of LA to form a chloroxy lactic acid intermediate (X) and $\mathrm{ArSO}_{2} \mathrm{NH}^{-}$ion. The latter anion on abstraction of an $\alpha$-proton from complex $\mathrm{X}$ forms the reduction product, PTS. In the rate-determining process (slow step (ii)), deprotonation of complex $\mathrm{X}$ and intramolecular rearrangements occur forming the next intermediate (complex $X^{\prime}$ ) which leads to pyruvic acid. The reaction of pyruvic acid with a second mole of the reactive oxidant species, $\mathrm{ArSO}_{2} \mathrm{NHCl}$, leads to a chloroderivative (complex $\mathrm{X}^{\prime \prime}$ ), which in a series of fast steps yields the oxidation end product, $\mathrm{CH}_{3} \mathrm{COOH}$. Scheme 2 is consistent with the reported mechanisms for similar redox reactions[13-17].

\section{Rate law derivation}

From the slow step in Scheme 1,

$$
\text { rate }=-\mathrm{d}[\mathrm{CAT}] / \mathrm{dt}=\mathrm{k}_{2}[\mathrm{X}]
$$

If $[\mathrm{CAT}]_{\text {tot }}$ represents the total effective concentration of the oxidant, CAT, then

$$
[\mathrm{CAT}]_{\mathrm{tot}}=\left[\mathrm{ArSO}_{2} \mathrm{NHCl}\right]+[\mathrm{X}]
$$

By making an appropriate substitution from equilibrium step (i) of Scheme 1 into eq. (13) and solving for [X], one obtains,

$$
\begin{gathered}
{[\mathrm{CAT}]_{\text {tot }}=[\mathrm{X}] /\left(\mathrm{K}_{1}[\mathrm{LA}]\right)+[\mathrm{X}] \text { or }[\mathrm{CAT}]_{\text {tot }}} \\
=[\mathrm{X}]\left\{\left(1+\mathrm{K}_{1}[\mathrm{LA}]\right) /\left(\mathrm{K}_{1}[\mathrm{LA}]\right)\right\} \\
\text { Or X }]=\mathrm{K}_{1}[\mathrm{CAT}]_{\mathrm{tot}}[\mathrm{LA}] /\left(1+\mathrm{K}_{1}[\mathrm{LA}]\right)
\end{gathered}
$$

Substitution for $[\mathrm{X}]$ from eq. (14) into eq. (12), one gets the rate law [eq. (15)] given below.

$$
\text { Rate }=\mathrm{K}_{1} \mathrm{k}_{2}[\mathrm{CAT}]_{\mathrm{tot}}[\mathrm{LA}] /\left(1+\mathrm{K}_{1}[\mathrm{LA}]\right)
$$

Since rate $=\mathrm{k}_{\mathrm{obs}}[\mathrm{CAT}]_{\text {tot }}$, eq. (15) can be transformed into eq. (16) as follows:

$$
\mathrm{k}^{\prime} \text { or } \mathrm{k}_{\mathrm{obs}}=\mathrm{K}_{1} \mathrm{k}_{2}[\mathrm{LA}] /\left(1+\mathrm{K}_{1}[\mathrm{LA}]\right) \text { or } 1 / \mathrm{k}_{\mathrm{obs}}
$$




$$
=\left(1 / \mathrm{K}_{1} \mathrm{k}_{2}[\mathrm{LA}]+1 / \mathrm{k}_{2}\right)
$$

The derived rate law (eq. (15)) is in good agreement with the experimental kinetic results such as a first-order dependence of the rate on [CAT], a fractional-order on [LA], and a zero-order each on $\left[\mathrm{H}_{2} \mathrm{SO}_{4}\right]$ and [PTS]. To test the validity of the above rate equation (15), a double reciprocal plot of $1 /[\mathrm{LA}]$ vs. $1 /\left[\mathrm{k}_{\mathrm{obs}}\right]$, based on eq. (16), when all other conditions were kept constant, was found to be linear $\left(\mathrm{r}^{2}=\right.$ 0.973). From the slope and intercept values of 2164.5 and 8392 , respectively, the formation constant $\left(k_{1}\right)$ and the decomposition constant $\left(\mathrm{k}_{2}\right)$ calculated for the standard run (at $323 \mathrm{~K},[\mathrm{CAT}]=1.00 \times 10^{-3} \mathrm{M},[\mathrm{LA}]=4.00 \times 10^{-2} \mathrm{M}$, and $\left[\mathrm{H}_{2} \mathrm{SO}_{4}\right]=5.00 \times 10^{-3} \mathrm{M}$ ) were found to be $3.88 \mathrm{M}^{-1}$ and 1.19 x $10^{-4} \mathrm{~s}^{-1}$, respectively. These values are supportive of the mechanism in Scheme 2.

The reaction mechanism and the derived rate law are also supported by the following facts: (i) the increasing concentration of the reduction product of the oxidant, PTS, does not influence the rate showing that it is not involved in any pre-equilibrium in the mechanism;(ii) Bronsted and Bjerrum[31] have described the primary salt effect on the reaction rate through the following relation:

$$
\log \mathrm{k}^{\prime}=\log \mathrm{k}_{\mathrm{o}}+1.02 \mathrm{Z}_{\mathrm{A}} \mathrm{Z}_{\mathrm{B}} \mu^{1 / 2} \underbrace{\mathrm{COOH}}_{\text {(reactive CAT species) }}
$$

where $\mu$ is the ionic strength of the medium, $A$ and $B$ are the reacting ions, $Z_{A}$ and $Z_{B}$ are charges on the respective species, $\mathrm{k}^{\prime}$ and $\mathrm{k}_{\mathrm{o}}$ are rate constants in the presence and absence of the added electrolyte, respectively.

According to eq. (17), a plot of $\log \mathrm{k}^{\prime} v s . \mu^{1 / 2}$ should be linear with a slope of $1.02 Z_{A} Z_{B}$ and intercept of $\log k_{0}$. As the slope of the line depends on $Z_{A} Z_{B}$, the reaction rate may increase, decrease or remain unaffected with the ionic strength variation in the reaction medium. In the present study, the variation of ionic strength of the medium does not affect the rate, which signifies that at least one of the reactant species is a neutral molecule as shown in slow step (ii) of Scheme 1. Hence, the observed zero ionic strength effect is consistent with the Bronsted-Bjerrum concept[31] for the proposed mechanism; and (iii) the fairly positive values of free energy and enthalpy of activation indicate that the transition state is highly solvated. Furthermore, the observed negative value of $\Delta \mathrm{S}^{\neq}$indicates that as a fraction of collisions becomes more stringent, the decomposition of the rigid activated complex involves a slow process. This is suggestive of the fact that the LA-CAT reaction is relatively more controlled by entropy than enthalpy.

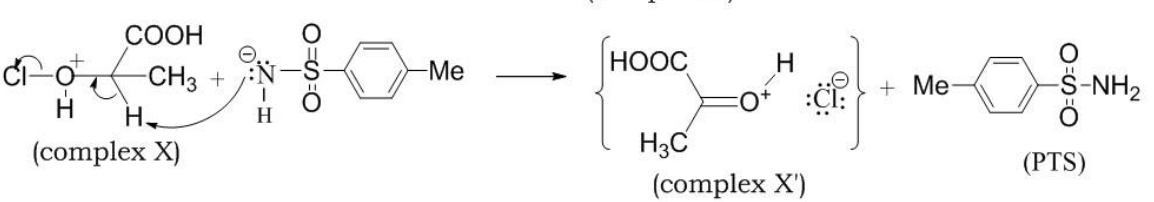
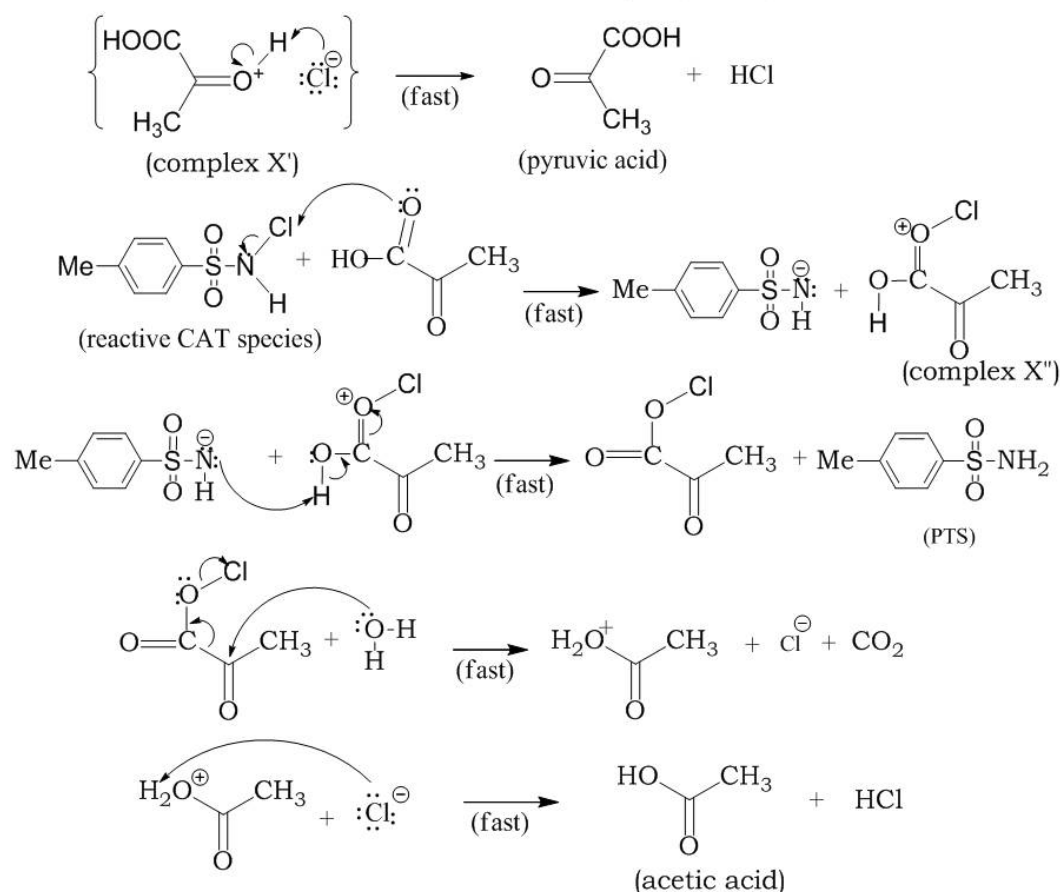

Scheme 2. Detailed electronic mechanism of LA oxidation by CAT in acid medium 


\section{Conclusions}

The LA-CAT reaction has been investigated in acid solutions. The reaction stoichiometry involving the LA oxidation to acetic acid by CAT has been found to be 1:2 (eq. (1). Kinetic results show that the redox reaction has the following experimental rate law: rate $=\mathrm{k}^{\prime}[\mathrm{LA}]^{0.80}[\mathrm{CAT}]\left[\mathrm{H}^{+}\right]^{0}[\mathrm{PTS}]^{0}$. The ionic strength and $\left[\mathrm{SO}_{4}{ }^{2-}\right]$ of the reaction medium have no effect on the rate. The activation parameters, $\mathrm{E}_{\mathrm{a}}, \Delta \mathrm{H}^{\neq}, \Delta \mathrm{G}^{\neq}$, and $\Delta \mathrm{S}^{\neq}$, have been determined to understand whether the reaction is controlled by entropy or enthalpy. The negative $\Delta \mathrm{S}^{\neq}\left(-280 \mathrm{JK}^{-1} \mathrm{~mol}^{-1}\right)$ indicates the rigid transition state formation and the entropy controlled reaction. A suitable mechanism consistent with the experimental observations has been proposed and a rate law has been derived.

\section{ACKNOWLEDGEMENTS}

Authors are grateful to the Western Illinois University Research Council for financial support.

\section{REFERENCES}

[1] R. Datta, Hydroxy carboxylic acids, in Kirk-Othmer Encyclopedia of Chemical Technology, $5^{\text {th }}$ ed, Seidel A.Wiley, Ed., Hoboken, NJ, Vol. 14, pp.114-134, 2005

[2] Soomro, A.H., Masud. T, and Anwaar, K., 2002, Role of lactic acid bacteria (LAB) in food preservation and human health - A Review., Pakistan J. Nutrition, 1(1), 20-24

[3] Mills, C.A. Navarro, M., Engel, E., Martinez, E. Ginebra, M.P., Planell, J., Abdelhamid Errachid, A., and Samitier, J., 2006, Transparent micro- and nano-patterned poly(lactic acid) for biomedical applications., J Biomed. Mater. Res. A., 76(4), 781-787

[4] Avinc, O., and Khoddami, A., 2009, Overview of poly(lactic acid) (PLA) Fibre Part I: Production, properties, performance, environmental impact, and end use applications of poly(lactic acid) fibres., Fibre Chem., 41(6), 50-56

[5] Lipinsky, E.S., and Sinclair, R.G., 1986, Is lactic acid a commodity chemical?, Chem. Engg. Prog,,82, 26-32

[6] Datta, R, Tsai S.P., Bonsignore, P., Moon, S.H., and Frank, J.R., 1995, Technological and economic potential of poly(lactic acid) and lactic acid derivatives., FEMS Microbiol. Rev., 16, 221-231

[7] Yadav, A.K., Chaudhari, A.B., and Kothari, R.M., 2011, Bioconversion of renewable resources into lactic acid: an industrial view., Crit. Rev. Biotechnol., 31(1), 1-19

[8] Jiao, Y.-H., Li, Y., Wang, S., Zhang, K., Jia, Y.-G., and Fu, Y., 2010, Layer by Layer assembly of poly(lactic acid) nanoparticles: A facile way to fabricate films for model drug delivery., Langmuir: The ACS Journal of Surfaces And Colloids, 26(11), 8270-8273

[9] J. David, "Drinking water criteria document for chloramines," Medical University of South Carolina, Health and Ecological
Criteria Division, 1994. (http://www.epa.gov/ncea/pdfs/wate r/chloramine/dwchloramine.pdf)

[10] Singh B., Singh A.K., Singh N.B., and Saxena, B.B.L.,1984, $\mathrm{Ru}$ (III) catalysis in oxidation of $n$-propanol and $n$-butanol by acidic solutions of bromamine-ULE., Tetrahedron. 40, 5203-5206

[11] Trieff, N.M., Made Gowda, N .M., and Sadagopa Ramanujam, V.M., 1980, Chloramine-T as a potential scrubbing agent: Removal of odorous sulfur-containing environmental pollutants., Bull. Environm. Contam. Toxicol, 24, 383-388

[12] Veeraiah, M.K., Ananda Murthy, A.S., and Made Gowda, N.M., 2010, Oxidation of $n$-propylamine and $n$-butylamine by chloramines-B and chloramine-T in basic medium: A kinetic study., Synth. React. Inorg. Met.-Org. Nano-Met. Chem., 40(4), 225-230

[13] Ramachandrappa, R., Puttaswamy, Mayanna, S.M., and Made Gowda, N.M., 1999, Kinetics and mechanism of oxidation of aspirin by bromamine-T, N-bromosuccinimide and N-bromophthalimide., Int. J. Chem. Kinet., 30(6), 407-414

[14] Venkatesha, B.M., Ananda, S., Mahadevappa, D.S., and Made Gowda, N.M., 1995, Kinetic and mechanistic studies of indigocarmine oxidation by chloramines- $\mathrm{T}$ and chlorine in acidic buffer media., Int. J. Chem. Kinet., 27(7), 663-674

[15] Khan, K., Raju, M.K., and Ud Din, K., 2004, Oxidation of lactic acid by water soluble (colloidal) manganese dioxide., Int. J. Chem. Kinet., 36: 359-366

[16] Wang, H.-Y., and Zhao, J.-F., 2003, Interaction of indigo carmine with cetyltrimethylammonium bromide and application to determination of cationic surfactant in waste water., Bull. Korean Chem. Soc., 24(10), 1444-1448

[17] Farah, M.E., Maia, M., and Rodrigues, E.B., 2009, Dyes in ocular surgery: principles for use in chromovitrectomy., Amer. J. Ophthalmol., 148, 332-340

[18] Hunt, I.V., 1939, The indigo carmine reaction as a test for chlorates and hypochlorites in milk., Analyst, 64, 653-657

[19] Dweck, A.C., 2002, Natural ingredients for colouring and styling., Int. J. Cosmet. Sci., 24(5), 287-302

[20] Komboonchoo, S., and Bechtold, T., 2009, Natural dyeing of wool and hair with indigo carmine (C.L. Natural Blue 2), a renewable resource based blue dye., J. Cleaner Production, 17, $1487-1493$

[21] E.H. Rodd, Chemistry of carbon compounds., Elsevier, Amsterdam,IVB: p.1093, 1960

[22] Keyvanfard, M., 2009, Kinetic-photometric determination of iodide based on its inhibitory effect on the bromated oxidation of indigo carmine in micellar medium., Asian J. Chem., 21(4), $2715-2720$

[23] Zaprozhets, O.A., and Biokon, S.L., 2007, A visual test method for determining selenium(IV) with indigo carmine immobilized on silica., J. Anal. Chem., 62, 188-189.

[24] Cholkar, K., Kouassi, G.K., Ananda, S., Veeraiah, M.K., and Made Gowda, N.M., 2011, Osmium(VIII)-catalyzed kinetics and mechanism of indigo carmine oxidation by chloramine-B in basic Medium., Synth. React. Inorg. Met.-Org. Nano-Met. Chem., 41(9), 1126-1134 
[25] E.A. Moelwyn-Hughes, Ed., Kinetics of reactions in solutions., Oxford University Press, London, pp. 297-299, 1947

[26] Campbell, M.M., and Johnson, G., 1978, Chloramine-T and related N-halogeno-N-metallo reagents., Chem. Rev., 78, 65-79

[27] Mallamma, Ananda, S., Rangaswamy, and Made Gowda, N.M., 2003, Kinetic and mechanistic studies of Pd(II) catalyzed oxidation of some $\alpha$-hydroxy acids by sodium N-bromobenzenesulphonamide in hydrochloric acid solutions., Synth. React. Inorg. Met.-Org. Chem., 33, 1555-1568
[28] Sushashini, M., Subramanian, M., and Rao,V.R.S., 1985, Determination of protonation constant of chormaine-B., Talanta, 32, 1082-1085

[29] Hardy, F.F., and Johnston, J.P., 1973, J. Chem. Soc., Perkin Trans. II, 742

[30] Narayanan, S.S., and Rao, V.R.S, 1983, Chlorine isotopic exchange reaction between chloramine- $\mathrm{T}$ and chloride ion., Radiochim. Acta, 32(4), 211-214

[31] K.J. Laidler, Reaction Kinetics: 2nd Ed., Tata Mc-Graw Hill, New Delhi, 1995 